\title{
Observational Study to Evaluate the Lipid Profile Abnormalities among Newly Diagnosed Hypertensive Patients
}

\author{
Sidhant Kumar ${ }^{1}$, Manish Kumar ${ }^{2}$ \\ ${ }^{1,2}$ Senior Residents, Department of Medicine, Patna Medical College and Hospital, Patna, Bihar, India \\ Corresponding Author: Sidhant Kumar
}

\begin{abstract}
Objective and Aim: Variations from the norm of lipid profile and hypertension frequently coincide. The present study was conducted to evaluate the lipid profile abnormalities among hypertensive patients.

Material and Method: This is a retrospective observational study conducted at a primary diabetes and cardiology clinic OPD among 200 patients whose clinical records are well maintained or fully available at the clinics registry. After getting individual patient consent the data collected and analysed to draw a study conclusion.
\end{abstract}

Result: $48.4 \pm 6.9$ years was the mean average age of study group whereas for the control group it was $49.3 \pm 5.9$ years. In the age group 40-49 years occurrence of hypertension was seen in extreme as compare to other age group. In study groups total cholesterol, triglyceride, HDL Cholesterol and LDL Cholesterol were significantly higher as compared to control group $(\mathrm{p}<0.05)$. Among the hypertensive subjects most frequently occurring abnormality was elevated TC $(78 \%)$, followed by elevated LDL (66\%).

Conclusion: Among newly diagnosed hypertensives lipid variations are highly prevalent as documented in this study. Hypertension is the one of the major risk factor for coronary artery disease and for this biologic interrelation between serum lipids and blood pressure further worsens the condition. Hence to prevent complications early detection and aggressive treatment of dyslipidemia in hypertensive patients should be carried out.

Keyword: Hypertension, Lipid profile, Cardiovascular Diseases.

\section{INTRODUCTION}

Raised blood pressure (BP) whether systolic or diastolic is established as a strong, independent risk factor for renal disease and for several cardiovascular (CV) disorders, including coronary heart disease (CHD), stroke, heart failure and peripheral artery disease. The importance of raised BP lies in the fact that it is one of the major risk factors for current global mortality. Indeed raised $\mathrm{BP}$, here defined as a systolic $\mathrm{BP}$ $>115 \mathrm{mmHg}$, is currently the biggest single contributor to death around the world whether the developed or developing world ${ }^{[1]}$. Based on large prospective observational data, both systolic and diastolic BP show a strong direct relationship with all major adverse cardiovascular events, including coronary heart disease (CHD), stroke, CV mortality and heart failure.

Dyslipidemic hypertension have been distinguished as autonomous hazard factors for fundamental hypertension are perceived as major modifiable cardiovascular disease (CVD) risk factors which are basically Abnormalities in serum lipid and lipoprotein levels (dyslipidemia) [2]. As compare than normotensives, in untreated hypertensives dyslipidemia is more typical as BP incrases. Among hypertensive people, dyslipidemia has been reliably revealed, in spite of the fact that no particular example. Among hypertensive patients than in the all inclusive community, many examinations have demonstrated that for all intents and purposes like total 
cholesterol (TC), triglycerides (TG), have a tendency to be more as often as possible strange ${ }^{[3]}$.

Abnormalities in serum lipid and lipoprotein levels is known to be related with adjustments with hypertension is known to be related with adjustments in lipid metabolism. Fundamental hypertension might be related with hypercholesterolemia show that weakened endothelium-dependent vascular unwinding in patients and in itself might be a modifiable hazard factor for hypertension as it has been recommended that low density lipoprotein (LDL) cholesterol ${ }^{[4]}$. On the rate of atheroma formation in human subjects, there is additionally articulated impact of BP. As gathered from different parts of the world after the post-mortem examination thinks about led on human coronary veins and aortas, atherosclerosis is broad and serious in hypertensive people than in normotensive [5].

The present study was conducted to evaluate the lipid profile abnormalities among hypertensive patients attending tertiary care hospital.

\section{MATERIAL AND METHOD}

This is a retrospective observational study conducted at a primary diabetes and cardiology clinic OPD among 200 patients whose clinical records are well maintained or fully available at the clinic's registry. After getting individual patient consent the data collected and analysed to draw a study conclusion.

All Type 2 diabetic patients without any clinical symptoms of cardiovascular involvement, blood pressure $<130 / 80 \mathrm{mmHg}$ and having normal ECG were included in the study. All Type 2 diabetes patients with other cardiac diseases like ischemic and hypertensive heart disease, cardiomyopathy, congestive heart failure and valvular heart disease.

Outcome measures of the treatment of T2DM included BMI (body mass index), SBP (systolic blood pressure), DBP (diastolic blood pressure), FPG (fasting plasma glucose), HbA1c (glycosylated hemoglobin level), Fasting Lipid profile, Urine routine and microscopy, ECG, Fundoscopy, Chest X-ray, Echocardiography (E/A ratio; left atrial size was assessed) were noted from the clinical records of the participants. Evidence of left ventricular diastolic dysfunction were considered as the E/A $<1$ and increase in LA size.

All study patients were described by demographic variables, background variables, and other variables with appropriate statistics: frequency tables (count and percent) for categorical variables and/or descriptive statistics (mean, SD, minimum, median, mode, and maximum) for continuous variables. The analysis was carried out by using SPSS version 20.0 and MS-Excel. T-Test was applied for continuous data.

\section{RESULT}

This study was conducted among 200 patients in which study group consists of 100 patients and the control group consists of 100 patients. $48.4 \pm 6.9$ years was the mean average age of study group whereas for the control group it was $49.3 \pm$ 5.9 years (table 1). It was also observed that study group were having higher weight than compare to control group. Entire noted demographic details were listed in table 1 .

Table 1: Demographic details

\begin{tabular}{|c|c|c|}
\hline Variables & $\begin{array}{ll}\begin{array}{l}\text { Study } \\
(n=100)\end{array} & \text { group }\end{array}$ & group \\
\hline Age (years) & $48.4 \pm 6.9$ & $49.3 \pm 5.9$ \\
\hline Male & 65 & 57 \\
\hline Weight (kg) & $70.8 \pm 7.2$ & $68.9 \pm 7.2$ \\
\hline Height $(\mathrm{cm})$ & $173.4 \pm 8.1$ & $181.1 \pm 7.3$ \\
\hline BMI $\left(\mathrm{kg} / \mathrm{m}^{2}\right)$ & $24.95 \pm 4.4$ & $23.46 \pm 5.1$ \\
\hline SBP $(\mathrm{mmHg})$ & $171.1 \pm 13.2$ & $117.6 \pm 10.8$ \\
\hline $\begin{array}{l}\text { DBP } \\
(\mathrm{mmHg})\end{array}$ & $98.8 \pm 9.7$ & $71.3 \pm 5.3$ \\
\hline
\end{tabular}

In the age group 40-49 years occurrence of hypertension was seen in extreme as compare to other age group.

Table 2 demonstrated the distribution of mean level of serum lipoproteins. In study groups total cholesterol, triglyceride, HDL Cholesterol 
and LDL Cholesterol were significantly higher as compare to control group $(\mathrm{p}<0.05)$ (table 2). From the above table, the mean total cholesterol was more among study group $(211.2 \pm 17.6 \mathrm{mg} / \mathrm{dl})$ than controls $(161.3 \pm 16.3 \mathrm{mg} / \mathrm{dl}) \quad(\mathrm{p}<0.05)$. The mean triglycerides were higher among control groups $(176.86 \pm 22.5 \mathrm{mg} / \mathrm{dl})$ than controls $(121.68 \pm 22.8 \mathrm{mg} / \mathrm{dl})$. The mean HDL was low among study group (42.64 \pm 4.81 $\mathrm{mg} / \mathrm{dl})$ than controls $(48.9 \pm 3.9 \mathrm{mg} / \mathrm{dl})$ $(\mathrm{p}<0.05)$. The mean LDL was higher among study group $(141.43 \pm 21.8 \mathrm{mg} / \mathrm{dl})$ than controls $(102.87 \pm 17.4 \mathrm{mg} / \mathrm{dl}) \quad(\mathrm{p}<0.05)$. Statistically significant difference was found in between the two groups $(\mathrm{p}<0.05)$.

Table 2: Mean level of serum lipoproteins

\begin{tabular}{|l|l|l|l|}
\hline Parameters & $\begin{array}{l}\text { Study group } \\
(\mathbf{n = 1 0 0})\end{array}$ & $\begin{array}{l}\text { Control group } \\
(\mathbf{n = 1 0 0})\end{array}$ & $\begin{array}{l}\text { P } \\
\text { Value }\end{array}$ \\
\hline $\begin{array}{l}\text { Total Cholesterol } \\
(\mathrm{mg} / \mathrm{dl})\end{array}$ & $211.2 \pm 17.6$ & $161.3 \pm 16.3$ & $<0.05$ \\
\hline $\begin{array}{l}\text { Triglyceride } \\
(\mathrm{mg} / \mathrm{dl})\end{array}$ & $176.86 \pm 22.5$ & $121.68 \pm 22.8$ & $<0.05$ \\
\hline $\begin{array}{l}\text { HDL- Cholesterol } \\
(\mathrm{mg} / \mathrm{dl})\end{array}$ & $42.64 \pm 4.81$ & $48.9 \pm 3.9$ & $<0.05$ \\
\hline $\begin{array}{l}\text { LDL- Cholesterol } \\
(\mathrm{mg} / \mathrm{dl})\end{array}$ & $141.43 \pm 21.8$ & $102.87 \pm 17.4$ & $<0.05$ \\
\hline
\end{tabular}

Among the hypertensive subjects most frequently occurring abnormality was elevated TC $(78 \%)$, followed by elevated LDL $(66 \%)$.

Table 3: Prevalence of serum lipid abnormality

\begin{tabular}{|l|l|l|}
\hline Lipid abnormality & $\begin{array}{l}\text { Study group } \\
(\mathbf{n = 1 0 0})\end{array}$ & $\begin{array}{l}\text { Control group } \\
(\mathbf{n = 1 0 0 )}\end{array}$ \\
\hline $\begin{array}{l}\text { Elevated TC (> 200 } \\
\mathrm{mg} / \mathrm{dl})\end{array}$ & $78(78 \%)$ & $1(1 \%)$ \\
\hline $\begin{array}{l}\text { Elevated LDL (>130 } \\
\mathrm{mg} / \mathrm{dl})\end{array}$ & $66(66 \%)$ & $3(3 \%)$ \\
\hline $\begin{array}{l}\text { Elevated TG (> 150 } \\
\mathrm{mg} / \mathrm{dl})\end{array}$ & $41(41 \%)$ & $4(4 \%)$ \\
\hline $\begin{array}{l}\text { Low HDL-C (<40 } \\
\mathrm{mg} / \mathrm{dl})\end{array}$ & $39(39 \%)$ & $2(2 \%)$ \\
\hline
\end{tabular}

\section{DISCUSSION}

Among primary newly diagnosed hypertensive patients present study mainly assessed the dyslipidemia. It has been observed in this study that in both the group male participants was in higher number. In a similar way study done by Jugal Kishore et al. and Anil Kumar Mahapatro et al. also reported higher number of male participants in both study group and in control group [6,7]. Our study demonstrated significant association go age and hypertension, in similar report was also observed by Vasan et al. among 1298 subjects found significant association of age with blood pressure ${ }^{[8]}$. In this study it has also been observed that in the age group 40-49 years occurrence of hypertension was seen in extreme as compare to other age group. These findings also co relates with the findings of several studies done previously ${ }^{[9-11]}$.

In this study it was also observed that in study groups total cholesterol, triglyceride, HDL Cholesterol and LDL Cholesterol were significantly higher as compare to control group $(\mathrm{p}<0.05)$. This findings also similar with the findings demonstrated in few previous trials ${ }^{[12,13]}$.

With increasing systolic or diastolic blood pressure in both sexes total and non HDL-C level increased significantly as documented in this study were also documented by some few other investigator previously ${ }^{[14,15]}$.

Meta-analysis of all clinical trials, to date, demonstrates that reducing BP reduces risk for stroke and coronary heart disease ${ }^{[16]}$. This lack of lower BP goal achievement is even true in CVD outcomes trials of diabetes and dyslipidemia.

The authors acknowledge several limitations of their data, including the methods of dichotomising the risk factors and others. Variation in large populations, attempting to subdivide these factors further would have likely led to a very complex and difficult article.

\section{CONCLUSION}

Among newly diagnosed hypertensives lipid variations are highly prevalent as documented in this study. Hypertension is the one of the major risk factor for coronary artery disease and for this biologic interrelation between serum lipids and blood pressure further worsens the condition. Hence to prevent complications early detection and aggressive treatment of dyslipidemia in hypertensive patients should be carried out. 


\section{REFERENCES}

1. Ezzati $\mathrm{M}$ et al. Selected major risk factors and global and regional burden of disease. Lancet 2002;360:1347-60.

2. W. B. Kannel,W. P. Castelli, T. Gordon, and P. M. McNamara, "Serum cholesterol, lipoproteins, and the risk of coronary heart disease. The Framingham study," Annals of Internal Medicine, vol. 74, no. 1, pp. 1-12, 1971.

3. R. R. Williams, S. C. Hunt, P. N. Hopkins et al., "Familial dyslipidemic hypertension. Evidence from 58 Utah families for a syndrome present in approximately $12 \%$ of patients with essential hypertension," Journal of the American Medical Association, vol. 259, no. 24, pp. 35793586, 1988.

4. Saha MS, Sana NK, and RanajitKS.Serum lipid profile of 6 . hypertensive patients in the northern region of Bangladesh. $\mathrm{J}$ bio sci2006, 14: 93- 8 .

5. Bravo EL: Metabolic factors and the sympathetic nervous system. Am J Hypertens 1989;2:339S-344S.

6. Jugal Kishore, Neeru Gupta, Charu Kohli, Neeta Kumar. Prevalence of Hypertension and Determination of Its Risk Factors in Rural Delhi. Hindawi Publishing Corporation. International Journal of Hypertension. 2016;5:1-6.

7. Anil Kumar Mahapatro, Surada Chandrika, Rajyalakshmi Chepuru. A study of lipid profile abnormalities among patients with essential hypertension attending tertiary care centre. International Journal of Contemporary Medical Research 2020; 7(1):A1-A4.

8. R. S. Vasan, A. Beiser, S. Seshadri et al. Residual lifetime risk for developing hypertension in middle-aged women and men: the Framingham Heart Study. The Journal of the American Medical Association.2002;287:1003-1010.

9. Pyadala N, Bobbiti RR, Borugadda R, Bitinti S, Maity SN, Mallepaddi PC, Polavarapu R. Assessment of lipid profile among hypertensive patients attending to a rural teaching hospital, Sangareddy. Int J Med Sci Public Health. 2017;6:71-74.

10. T.V Murali Krishna, Vijaya Kumar Vasa, V A Deepika Ponnuru. The study of correlation between dyslipidemia and hypertension and its complications in 30-70 years age group. IAIM, 2016;3: 84-90.

11. J Idemudia, E Ugwuja. Plasma Lipid Profiles in Hypertensive Nigerians. The Internet Journal of Cardiovascular Research. 2008;6:1-6.

12. Charles U. Osuji,1 Emeka G. Omejua,2 Emmanuel I. Onwubuya,1 and Gladys I. Ahaneku1. SerumLipid Profile of Newly Diagnosed Hypertensive Patients in Nnewi, South-East Nigeria. Hindawi Publishing Corporation. International Journal of Hypertension 2012;6:1-7.

13. Kavindra Borgaonkar, Ranjit Patil, Pradeep Ben. Lipid profile in hypertension: A meta analysis using western countries data. MedPulse - International Medical Journal 2016;3: 967-973.

14. Bonaa. Dag S. Association between blood presure and serum lipids in a populationThe Tromso Criculation 1991:83 (4): 130513

15. Kelishadi R, Alikhani S, Delavari A, Alaedini F, Safaie A, Hojatzadeh E. Obesity and associated lifestyle behaviours in Iran: Findings from the national noncommunicable disease risk factor surveillance survey. Public Health Nutr. 2008; 11:246-51

16. Staessen JA, Li Y, Thijs L, et al. Blood pressure reduction and cardiovascular prevention: an update including the 20032004 secondary prevention trials. Hypertens Res 2005;28(5):385-407.

How to cite this article: Kumar S, Kumar M. Observational study to evaluate the lipid profile abnormalities among newly diagnosed hypertensive patients. International Journal of Research and Review. 2021; 8(3): 5-8. 